\title{
Internet Reviews
}

CyberAtlas. Access: http://cyberatlas.

internet.com.

Internet technology permeates almost every area of daily life. Researchers want data, statistics, and survey information about this booming industry. Established in 1996, CyberAtlas pulls together information about the Internet from a variety of Web-based resources.

Rather than conducting its own research, CyberAtlas gathers Internet-related surveys and data from governmental, educational, commercial, and independent organizations and presents this information in two major groups: "Big Picture" and "Markets." "Big Picture" includes the subcategories of statistics toolbox, demographics, geographics, hardware, and traffic patterns. "Markets" covers advertising, B-to-B (business-to-business communications), broadband, education, finance, healthcare, professional, retailing, small business, travel, and wireless.

New articles are added daily, and older articles are archived (dating back to October 1998). Examples of article topics include the most highly visited sites on the Web, dot com career trends, numbers of wired classrooms in the United States, and the latest in wireless

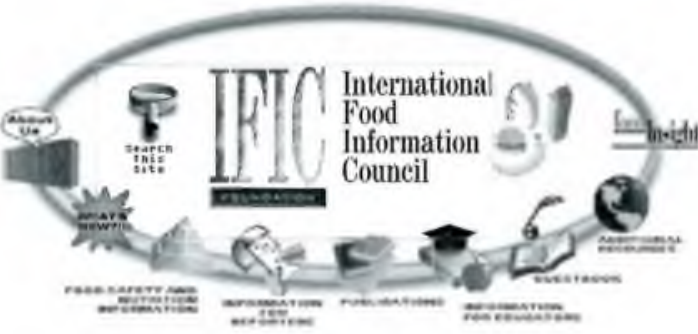
technology. A free text search with Boolean operators allows the user to search the entire CyberAtlas site. Each article summarizes the original study or survey presented and provides a link to the source of the information. Articles can be e-mailed or reformatted for printing.

Although CyberAtlas does have guidelines for the types of information it will present on the site, it does not comment on the validity or thoroughness of the survey methods used by the original producer of the information. Users of the site may want to visit the original source of the information to find out what methods of data collection and analysis were used to produce the results presented by CyberAtlas.
While this resource comes from the commercial sector, all of the information presented is free. The site is not commercial-free, though; ads for software and hardware appear throughout CyberAtlas, which is owned by internet.com. CyberAtlas does not include information on specific products and services.

This site will prove to be helpful for anyone doing research on the Internet, its use, and future Internet technologies. It would be particularly useful to students in business, marketing, education, computer science, journalism, political science, and the health sciences Doralyn H. Edwards, University of Wyoming, doralyn@uwyo.edu

\section{IFIC: International Food Infor- mation Council Foundation. Access:}

http://ificinfo.health.org.

The International Food Information Council Foundation (IFIC) is a nonprofit organization founded in 1985 to make scientific research reports in the field of food safety and health more easily understood by educators, journalists, and others who provide information to consumers. Its focus is primarily on U.S. issues, but it also works with independent food organizations in other countries. The food, beverage, and agricultural industries support IFIC.

The site is organized into sections such as "What's New," "Food Safety and Nutrition Information," "Information for Reporters," and "Information for Educators." There is also a link to IFIC's bimonthly publication, Food Insight. The site is easily searchable using Boolean operators and presents information from 1993 to 2001, but some of the information on timely topics seems to be dated.

Joni R. Roberts is associate university librarian for public services and collection development at Willamette University, e-mail: jroberts@willamette.edu, and Carol A. Drost is associate university librarian for technical services at Willamette University, e-mail: cdrost@willamette.edu 
The strength of the site is the suggested guidelines for critically evaluating information about food and health. These guidelines appear throughout the site, but are covered indepth in "Information for Reporters." One informative article offers a guide to understanding and interpreting scientific papers and includes a description of the methodologies and key definitions. Journalism and communication students, or others concerned with evaluating information may find these pages useful.

The information provided for educators is limited, including a small number of sample lesson plans and articles. The rest of the page lists Food Insight reprints and other materials that may be purchased from IFIC.

"Food Safety and Nutrition Information" is broken down into subjects ranging from biotechnology and food to health tips. The many articles in this section tend to vary in depth and quality; some have authors and references and others do not. Most are too shallow for an undergraduate research paper, but the general public may find them useful. All the articles support the use of biotechnology in agriculture. No mention is made of the opposing arguments.

With the exception of the evaluation information, the site is perhaps too superficial to be of much use to college students. By trying to make the information more understandable for the general public, IFIC has watered down its usefulness for academic papers. Nevertheless, the site may provide students with a starting point for research. _Carol McCulley, Linfield College, cmccull@ linfield.edu

Editors' note: IFIC informs us that they will soon be releasing a revised version of their site at http://ific.org.

opensecrets.org. Access: http://www.

opensecrets.org.

This site is maintained by the Center for Responsive Politics, which describes itself as "a non-partisan, nonprofit research group that tracks money in politics," mostly at the federal level. It accepts no money from businesses or labor unions. Its aim is "creating a more educated voter, an involved citizenry, and a more responsive government."

\section{Alutivi: opensecrets.org}

The site offers a tour, quickly introducing a user to the kinds of information available and giving examples of how to analyze the data. Nearly all the data originates from the Federal Election Commission (FEC) and is clearly presented in easy-to-read tables, graphs, and logically organized links. The fundamental problem with any site relying on FEC data is that much campaign financing is controlled by groups using legal loopholes, such as issue advertising, to avoid putting any information on the public record.

The site's information is arranged in four broad categories: "Who's Giving," "Who's Getting," "Get Local," and "News and Issues." "Who's Giving" profiles 121 industries, labor unions, and single-issue groups. Each profile contains a summary of donations going back to 1990 , a list of top contributors, and a list of all recipients. It is also possible to look up individual donors, companies, PACs, and softmoney contributors. The database includes all donations of $\$ 200$ or more reported to FEC.

"Who's Getting" covers the presidential race, congressional races, Congress itself, congressional committees, and political parties. Profiles of individual politicians list contributions by geographical area, sector, industries or interest groups, PACs, and individuals. Each member of Congress has a link to descriptions of legislation he or she sponsored. Each congressional committee's jurisdiction, membership, and the top contributors to each member are provided. "Get Local" provides access to data arranged geographically. Again, the data describes who gives and who gets at the federal level. One can look at the data from a statewide perspective down to contributions listed by zip code. Many of the state profiles contain links to other sites with state-level information on campaign finance. "News and Issues" includes descriptions of current hot topics, such as prescription drugs, with lists of contributions made by interested parties, for example the pharmaceutical industry.

Professors, upper-level undergraduates and graduate students in such fields as political science, journalism, and law would find the information at opensecrets.com valuable.

An earlier version of this site was previously reviewed by Doralyn $\mathrm{H}$. Edwards, "Internet Reviews," CERL News 59 (1998): 709._Sarah Cogan, Eastern Michigan Iniversity Library, sarah.cogan@online.emich.edu 